that their RA was not well controlled. The most common participant goal was to improve or maintain physical function. Barriers to RA and flare management included: 1) Patient Level- lack of knowledge of how to manage flares and a reluctance to change or use medications, related to concerns about potential side effects, and limited understanding of the potential benefits; 2) Provider Levelinadequate communication between patient and provider, specifically in relation to flare management and; 3 ) Health System Level- difficulty navigating insurance, handling coverage gaps, affording high medication costs. Facilitators of RA and Flare management included: 1) Patient Level- successful use of non-medication approaches to disease management and the willingness to initiate conversation with their provider about changing medications and; 2) Provider Level- a positive relationship with their provider, including having trust in the provider, easy access to the provider, and positive communication.

Conclusions: We identified patient-, provider and health system-barriers and facilitators experienced by RA patients achieving their treatment goals. A common theme that emerged was inadequate shared decision making between patients and their providers related to lack of patient knowledge, inadequate communication, and mistrust.

Disclosure of Interest: C. Lemay Grant/research support from: Pfizer Inc, K. Mazor Grant/research support from: Pfizer Inc, J. Kremer Shareholder of: Corrona, Grant/research support from: Abbvie, Genentech, Lilly, Novartis, Pfizer, Employee of: Corrona, Speakers bureau: Genentech (non-promotional only, W. B. Nowell: None declared, C. Bingham III Consultant for: Bristol-Myers Squibb, J. Curtis Grant/research support from: Roche/Genentech, UCB, Janssen, Corrona, Amgen, Pfizer, BMS, Crescendo, AbbVie, Consultant for: Roche/Genentech, UCB, Janssen, Corrona, Amgen, Pfizer, BMS, Crescendo, AbbVie, E. Ruderman Grant/research support from: Pfizer Inc, Amgen, Consultant for: AbbVie, Amgen, Lilly, Novartis Pharmaceutical Corporation, Pfizer Inc., Janssen Pharmaceutica Product, L.P., L. Harrold Shareholder of: Corrona, Grant/research support from: Pfizer Inc, Consultant for: Roche Pharmaceuticals, Employee of: Corrona DOI: 10.1136/annrheumdis-2017-eular.3930

\section{SAT0751-HPR THE RELATIONSHIP BETWEEN ANAEROBIC EXERCISE CAPACITY AND ISOMETRIC LOWER EXTREMITY MUSCLE STRENGTH IN CHILDREN WITH JUVENILE IDIOPATHIC ARTHRITIS}

D. Bayraktar ${ }^{1}$, S. Savci ${ }^{2}$, E. Manci $^{3}$, O. Altug-Gucenmez ${ }^{4}$, B. Makay ${ }^{4}$, N. Illcin ${ }^{2}$ S.E. Unsal ${ }^{4}{ }^{1}$ Faculty of Health Sciences, Department of Physiotherapy and Rehabilitation, Izmir Katip Celebi University; ${ }^{2}$ School of Physical Therapy and Rehabilitation; ${ }^{3}$ Institute of Health Sciences; ${ }^{4}$ Faculty of Medicine, Division of Pediatric Rheumatology, Dokuz Eylul University, Izmir, Turkey

Background: Juvenile idiopathic arthritis (JIA) is a chronic disease that occurs before the age of 16 years. It was shown that anaerobic exercise capacity, which is important for most daily activities in children such as jumping, hoping and climbing was diminished in JIA. Previous studies showed that anaerobic exercise capacity was related to well-being level, functional status, and aerobic exercise capacity in JIA. However, no data is available about the relationship between lower extremity muscle power and anaerobic exercise capacity in children with JIA.

Objectives: To determine the possible relationships between lower extremity muscle strength and anaerobic capacity.

Methods: Forty-six children with JIA (14 F, $32 \mathrm{M}$ ), with a mean age of $13.74 \pm 2.29$ years (min-max: 9-17 years) were included in the study. Isometric lower extremity muscle strength was assessed with a hand-held dynamometer at the end points of knee flexion, knee extension, hip flexion and hip extension movements, which are generated from gross lower extremity muscles and important for anaerobic power. All the muscle testing was performed on the right leg. Anaerobic exercise capacity was measured performing a 30-second Wingate test. Both absolute and per kilogram values for peak power and average power were noted. The relationships between the parameters were determined with Pearson's correlation coefficient. (Relationship levels were interpreted as $0.05-0.30$ : low correlation; 0.30-0.40: low-moderate correlation; $0.40-0.60$ : moderate correlation; $0.60-0.75$ : good correlation; $0.75-1.00$ : good-excellent correlation.

Results: All children completed the assessments without any adverse effects. Demographics, average isometric lower extremity muscle strengths and param-

Table 1. Demographics, isometric lower extremity muscle strength and anaerobic exercise capacity parameters

\begin{tabular}{lc}
\hline & Mean \pm SD \\
\hline Age (years) & $13.74 \pm 2.29$ \\
Height $(\mathrm{cm})$ & $159.72 \pm 11.08$ \\
Weight $(\mathrm{kg})$ & $53.76 \pm 14.95$ \\
BMl $\left(\mathrm{kg} / \mathrm{m}^{2}\right)$ & $20.76 \pm 3.92$ \\
Hip Flexion $(\mathrm{kg})$ & $16.81 \pm 5.47$ \\
Hip Extension $(\mathrm{kg})$ & $13.57 \pm 4.50$ \\
Knee Flexion $(\mathrm{kg})$ & $17.72 \pm 5.83$ \\
Knee Extension $(\mathrm{kg})$ & $22.08 \pm 6.94$ \\
Peak Power $(\mathrm{W})$ & $386.26 \pm 184.08$ \\
Peak Power $(\mathrm{W} / \mathrm{kg})$ & $6.99 \pm 2.33$ \\
Average Power $(\mathrm{W})$ & $287.69 \pm 129.53$ \\
Average Power $(\mathrm{W} / \mathrm{kg})$ & $5.22 \pm 1.60$ \\
\hline SD: Standard Deviation; $\mathrm{cm}$ : centimeters; $\mathrm{kg}:$ kilogram; m: meter; W: watt; W/kg: watt/kilogram.
\end{tabular}

Table 2. The relationships between isometric muscle strength and anaerobic exercise capacity parameters

\begin{tabular}{lcccc}
\hline & $\begin{array}{c}\text { Peak Power } \\
(\mathrm{W})\end{array}$ & $\begin{array}{c}\text { Peak Power }) \\
(\mathrm{W} / \mathrm{kg})\end{array}$ & $\begin{array}{c}\text { Average Power } \\
(\mathrm{W})\end{array}$ & $\begin{array}{c}\text { Average Power } \\
(\mathrm{W} / \mathrm{kg})\end{array}$ \\
\hline Hip Flexion $(\mathrm{kg})$ & $0.688^{\star}$ & $0.629^{\star}$ & $0.636^{\star}$ & $0.552^{*}$ \\
Hip Extension $(\mathrm{kg})$ & $0.618^{\star}$ & $0.532^{\star}$ & $0.581^{*}$ & $0.458^{*}$ \\
Knee Flexion $(\mathrm{kg})$ & $0.642^{\star}$ & $0.530^{\star}$ & $0.630^{\star}$ & $0.494^{\star}$ \\
Knee Extension (kg) & $0.647^{\star}$ & $0.465^{\star}$ & $0.670^{\star}$ & $0.469^{\star}$ \\
\hline
\end{tabular}

Pearson Correlation Test; kg: kilogram; W: watt; W/kg: watt/kilogram. ${ }^{*}$ Significance at level $<0.001$.

eters related to the anaerobic exercise capacity testing were shown at Table

1. Moderate to good correlations were determined between isometric muscle strength and anaerobic exercise capacity parameters $p<0.001$ (Table 2).

Conclusions: The results of this study suggested that lower extremity muscle strength might influence the anaerobic exercise capacity. Exercise regimes including lower extremity strengthening might help improving anaerobic exercise capacity in children with JIA.

Disclosure of Interest: None declared

DOI: 10.1136/annrheumdis-2017-eular.5697

\section{SAT0752-HPR THE MEASUREMENT OF PATIENTS' EXPECTATIONS OF A MULTIDISCIPLINARY AND DEDICATED FIBROMYALGIA PROGRAM}

D. Xhaxho, A.A. Borg, C. Mercieca. Rheumatology, Mater Dei Hospital, Swatar, Malta

Background: Fibromyalgia (FM) is a chronic and multidimensional condition impacting the physical health and psychosocial state of the individuals. In addition to performing clinical and psychological assessments, evaluating patients' expectations may help address their specific needs and improve outcomes.

Objectives: The aim of this study was to assess the expectations of a cohort of FM patients participating in a multidisciplinary, dedicated fibromyalgia program. Methods: This was a survey of 86 consecutive FM patients who were initiating a multidisciplinary program delivered by a rheumatologist, nurse, physiotherapist, occupational therapist, psychotherapist and GP with a special interest in FM. Patients were diagnosed using the 2010 ACR diagnostic criteria. Demographic data, Widespread Pain Index (WPI), Symptom Severity Score (SSS) were recorded. Patients filled in the self-administered questionnaires including the Revised fibromyalgia impact questionnaire (FIQR), Hospital Anxiety and Depression Scale (HADS) and a patients' expectations questionnaire. The latter consisted of both open ended and closed questions using a five- point Likert scale ( $1=$ strongly agree to $5=$ strongly disagree) about the following domains; physical, psychological, coping and social aspects.

Results: Eighty six patients ( $92 \%$ females) participated in the survey. The average age was 51.2 years (SD 10.60) and mean duration of symptoms 13.3 years (SD 11.17). The mean HADS-A was 11.6 (SD 4.37), HADS-D 8.67 (SD 3.47) and FIQR 55.9 (SD 21.64). In response to an open question about what was their main expectation from this program, just over half of the patients $(52.3 \%)$ reported improvement of pain and fatigue as their most important outcome. This was followed by improved quality of life (19.3\%), being able to cope better with ADLs, family and work (17.4\%), obtain more knowledge about the condition $(5.8 \%)$, while $15.1 \%$ did not have any expectations. When asked to rate their expectations for each specific domain: $64 \%$ expected significant improvement of physical symptoms, $74 \%$ to be able to cope better with family, hobbies and work and $66 \%$ expected an improvement of their psychological state, namely depression and anxiety. By the end of the program, $66 \%$ of the patients expected to have minimal or no symptoms. When asked to identify any lifestyle changes which could help, $30.2 \%$ mentioned a better work-life balance, $12.8 \%$ starting an exercise routine, $10.5 \%$ weight loss, $11.6 \%$ a mixture of house adaptations while $34.9 \%$ could not come up with any suggestions.

Conclusions: Expectations of fibromyalgia patients were high in all domains. This study highlights the need for multidimensional assessment and a personalised treatment approach in managing fibromyalgia. Moreover, it is very important to assess patients' expectations in order to guide interventions and set realistic achievable goals which are acceptable to both patients and clinicians. Patients' expectations are an important patient reported outcome measure, which need to be assessed.

\section{References:}

[1] Goffaux P, De Souza J, Potvin S, Marchand S(2009) Research papers: Pain relief through expectation supersedes descending inhibitory deficits in fibromyalgia patients. Pain 145:18-23.

[2] Hamnes B, Hauge M, Kjeken I, Hagen K (2011)' I have come here to learn how to cope with my illness, not to be cured': A Qualitative Study of Patient Expectations Prior to a One-Week Self-Management Programme. Musculoskeletal Care 9(4):200-210.

Disclosure of Interest: None declared

DOI: 10.1136/annrheumdis-2017-eular.1599 